\title{
Militarização das escolas e a narrativa da qualidade da educação
}

\section{Militarization of schools and the narrative of quality of educacion \\ Militarización de las escuelas y la narrativa de la calidad de la educación \\ DANIEL CALBINO PINHEIRO \\ RAFAEL DIOGO PEREIRA GERUZA DE FÁTIMA TOME SABINO}

Resumo: Por meio de uma pesquisa documental e bibliográfica o trabalho tem por objetivo analisar as concepções e condições para a qualidade manifesta na defesa dos colégios militares e escolas militarizadas. Enquanto resultados mostraremos que por trás do resgate da pedagogia militar da educação, os padrões de qualidade reproduzem a mesma dinâmica dos sistemas de avaliação dos governos anteriores, silenciando ainda as condições materiais que legitimam os supostos desempenhos acadêmicos.

Palavras-chave: Qualidade da educação, colégios militares, militarização das escolas.

Abstract: Through a documentary and bibliographic research, this work aims to analyze the conceptions and conditions of the quality manifest in the defense of military and militarized schools. As result, it will show that behind the rescue of the pedagogy of teacher authority, quality standards reproduce the same dynamics of the evaluation systems of previous governments, still silencing the material conditions that legitimize the supposed academic performances.

Keywords: Quality of education, military schools, the militarization of education.

Resumen: A través de una investigación documental y bibliográfica, el trabajo tiene como objetivo analizar las concepciones y condiciones de la calidad manifiesta en la defensa de los colegios militares y las escuelas militarizadas. Como resultados, mostraremos que detrás del rescate de la pedagogía militar de educación, los estándares de calidad reproducen la misma dinámica de los sistemas de evaluación de gobiernos anteriores, silenciando aún las condiciones materiales que legitiman los supuestos rendimientos académicos.

Palabras clave: Calidad de la educación, colegios militares, militarización de las escuelas. 


\section{INTRODUÇÃO}

A pesquisa mostrou que o nível de educação atravessa momento crítico, refletido no baixo desempenho escolar de seus alunos, destacando-se, problemas de alfabetização, falta de domínio de capacitações para escrever com correção e desconhecimento de noções básicas de aritmética elementar.

A citação acima parece uma das frases ou relatos recentes, explicitados nas manchetes dos telejornais brasileiros sobre a "baixa qualidade" da Educação Básica. No entanto, o trecho foi retirado de um relatório elaborado por Vianna (1989, p.98) há três décadas para o Instituto Nacional de Estudos e Pesquisas Educacionais (INEP), ao analisar o desempenho de estudantes do ensino básico do país.

Se o dito problema da qualidade na educação não parece atual, na fala do recém-eleito presidente da república tem tido uma piora em consequência da perda da autoridade e de disciplina do professor em sala de aula. A alternativa para ele passa pela criação de instituições pautadas em pedagogias militares que "estão à frente em grande parte das demais", porque "ainda impõem hierarquia e autoridade aos alunos" (DOLZAN, 2018, p.1).

A militarização das escolas no atual governo se fundamenta no decreto $\mathrm{n}^{\circ}$ 9.665, de 2 de Janeiro de 2019 e no documento lançado em 11 de Julho de 2019 denominado "Compromisso Nacional pela Educação Básica”, os quais propõem: "A criação de colégios militares "tradicionais" em todos os Estados, gestados pela esfera federal (marinha, exército e aeronáutica); e a expansão da gestão compartilhada entre sociedade civil e militar, a partir de escolas cívico-militares, a cabo dos Estados e Municípios".

A expressão 'cívico-militar', cunhada e disseminada pelo governo federal, é passível de problematização. Do ponto de vista discursivo, a aproximação entre os termos cívico e militar acena para uma aproximação harmônica ou, talvez, para um equilíbrio entre essas duas dimensões no contexto da escola. Contudo, como veremos no decorrer deste artigo, a transposição das escolas para o modelo 'cívico-militar' acarreta, dentre outros fatores, impactos diretos sobre a autonomia do corpo docente e o cerceamento de liberdades fundamentais dos estudantes. $O$ fenômeno da militarização tem apresentado intensa ampliação nos últimos anos. Entre 2013 e 2017, as escolas estaduais geridas pela Polícia Militar e Bombeiros saltaram de 39 para 122 em 18 estados (SANTOS; PEREIRA, 2018; CABRAL, 2018) e, até meados de 2019, registram-se 203 escolas militarizadas em 23 estados e no Distrito Federal (BRASIL, MEC, 2019). 
Chama a atenção que, se a gestão das escolas por militares é preconizada por governantes que defendem o modelo, pesquisas recentes também apontam para o apoio de parte da população para resolver o problema da qualidade de ensino ${ }^{1}$. A suposta melhoria do rendimento de estudantes através da militarização vem propagando um ideal de modelo de educação a ser adotado (GUIMARÃES, 2017; ALVES; TOSCHI; FERREIRA, 2018).

Frente às narrativas construídas em prol do uso de regras rígidas para gerenciar a educação, este artigo busca identificar as concepções e condições para a qualidade manifesta na onda da militarização das escolas. Para tal, buscaremos situar a narrativa à luz das transformações da qualidade ao longo da educação brasileira, bem como, em relação às condições político-pedagógicas que sustentam os supostos resultados da qualidade nas escolas militarizadas ${ }^{2}$.

Em termos metodológicos, este artigo está ancorado em uma pesquisa documental e bibliográfica nos decretos, legislações e documentos que regem o ensino público brasileiro, bem como, a partir da análise de matérias disponíveis na grande mídia que apresentam narrativas em defesa da qualidade da educação a partir das pedagogias militares.

\section{AS CONCEPÇÕES DE QUALIDADE NA HISTÓRIA DA EDUCAÇÃO}

A discussão sobre a qualidade da educação no Brasil se populariza a partir do final da década de 1980, ocasionada por, pelo menos, dois fatores. O primeiro se refere à mudança paradigmática nas políticas públicas. Os sistemas de massificação da educação, a partir do acesso das camadas populares, passaram a representar a necessidade de distinguir outras dimensões de qualidade (CASASSUS, 2009; MARCHELLI, 2010; XIMENES, 2014).

\footnotetext{
$1 \quad$ No ano de 2015, um programa de televisão da emissora Bandeirantes emitiu uma enquete online cuja pergunta era: "Você é a favor da militarização das escolas públicas"? Ainda que a pesquisa não abordasse o número e o perfil dos respondentes, os resultados apontaram para $90 \%$ favoráveis ao modelo militar. Em similaridade, no ano de 2019, uma pesquisa realizada pelo Instituto Exata OP no Distrito Federal, indica que de um total de 925 pessoas entrevistadas, 84,9\% são favoráveis ao modelo implantado na região. Na classe econômica de perfil A (de maior poder aquisitivo) a aprovação chegava a 95\% (CAMPOS, 2019).
}

2 Neste trabalho as escolas militarizadas se referem às 203 escolas que haviam, até 2018, passado por processos de militarização nos 23 Estados do Brasil e no Distrito Federal. Além disso, é válido apontar para a existência de 13 Colégios Militares do Exército que não integram essa lista, por nascerem vinculados ao Ministério da Defesa e criados com a função específica de formar quadros para o exército, além de atender os filhos dos militares, disponibilizando um pequeno percentual de vagas para alunos proveniente de famílias civis. 
O segundo está relacionado às influências internacionais na importação de modelos de gestão de empresas privadas para contextos públicos. Sob a onda da qualidade total, os mecanismos de padronização e mensuração passaram a influenciar o sistema de educação no Brasil, cuja ideia é padronizar para comparar (OLIVEIRA; ARAUJO, 2005; DIAS SOBRINHO, 2008).

Mas, o que é qualidade? O termo advém do latim, qualitas, cuja procedência também é do grego, poiótês, que significa definidor de uma categorização. A qualidade tem sido considerada como uma agregação que confere valor superior a um bem, a um serviço ou a um sujeito. Trata-se de um atributo ou predicado virtuoso pelo qual esse sujeito, bem ou serviço se distingue de outros (CURY, 2010).

Morosini (2001) e Davok (2007) citam que, na literatura, o conceito de qualidade se aproxima de um conjunto de propriedades, atributos e condições inerentes a um objeto e que são capazes de distingui-lo de outros similares, classificando-o como o atributo que permite aprovar, aceitar ou refutar o objeto com base em um padrão de referência. Assim, qualidade implica em uma ideia de comparação.

No entanto, no campo da educação, a qualidade admite uma variedade de interpretações, dependendo da concepção que se tenha sobre o que esses sistemas devem proporcionar à sociedade. Uma educação de qualidade pode significar tanto aquela que possibilita o domínio eficaz dos conteúdos previstos, como aquela que desenvolve a máxima capacidade técnica para servir ao sistema produtivo ou, ainda, promover o espírito crítico e fomentar o compromisso para transformar a realidade social (DAVOK, 2007).

Se a qualidade na educação é uma distinção entre medidas (condicionando a forma de avaliar), que possui como pressuposto uma concepção anterior do que se entende por educação, questiona-se: Quem define os padrões de comparação e a quem atende a qualidade na Educação Básica? (DIAS SOBRINHO, 2008; CABRITO, 2009).

A história da educação brasileira é marcada, como pano de fundo, por mudanças e continuidades nas concepções da qualidade. Fonseca (2009), ao analisar os planos brasileiros de educação sobre a dinâmica socioeconômica e cultural observa que as primeiras discussões se iniciaram em 1932, promovidas pelo Manifesto dos Pioneiros.

A Constituição Brasileira de 1934 incorporou ideias do Manifesto, estabelecendo o ensino primário integral, gratuito, de frequência obrigatória e extensiva aos adultos. O ideal de qualidade da educação básica se movia pela 
adoção de uma pedagogia que facilitasse a individualização do educando pela atividade livre e espontânea, estimulando a atividade criadora da criança por meio do exercício prático.

Porém, a instauração do Estado Novo reformulou os planos de educação. A partir de 1937, com o apoio de setores militares e católicos, o governo lançou um plano de educação que inseriu o ensino religioso e moral cívico, como espaço de aprendizagem de valores de hierarquia e disciplina dos Homens. Tais valores se tornaram referência para a qualidade que buscava a formação de um indivíduo útil e disciplinado para um Estado que queria ser industrial e nacionalista.

As décadas de 1950 apresentaram uma continuidade no ideal de qualidade na formação de um modelo de sujeito útil para o mercado de trabalho. No governo de Juscelino Kubitschek, a educação reproduziu o programa de metas, cujo propósito era preparar técnicos para a industrialização de base. Nesse período, a concepção de qualidade da educação se aproxima da produção de competências para o emprego e agregação de valor à mão de obra no mercado de trabalho.

O ano de 1959 é marcado pelo Manifesto dos Educadores, que contrapõem uma alternativa social ao enfoque economicista. A qualidade não deveria se fundar em um saber exclusivamente de natureza técnica, mas abrir a percepção do educando para compreender as condições políticas com que se defronta e prepará-lo para o empenho coletivo de superação do atraso do país (FONSECA, 2009).

Porém, o golpe militar de 1964 acarretou a continuidade do modelo de educação que apreendia a qualidade enquanto um mecanismo de formação de mão de obra para o mercado. Ao afirmar a padronização como princípio, a educação distanciou-se mais das ideias dos pioneiros de 1933 e 1959. A qualidade definida pelo Ministério de Educação (BRASIL, MEC, 1971, p.15) era "formar um cidadão capaz de participar eficazmente das atividades produtivas da nação".

O fim do regime militar e a abertura gradual da economia foram acompanhados por mudanças no acesso à Educação Básica. Até 1971, para o acesso ao ginasial, não bastava concluir o Ensino Fundamental; necessitava-se da aprovação em um exame de admissão. Portanto, uma minoria conseguia ter acesso aos níveis mais elevados. Com a reforma da educação no governo militar, a obrigatoriedade da escolarização de oito anos gerou um paradoxo: se, por um lado, expandiram-se as oportunidades de acesso e permanência no sistema escolar para amplas camadas da população, por outro, suscitou-se uma massificação do acesso à educação básica em um momento em que os gastos com educação atingiam patamares mais baixos em decorrência da desvinculação mínima de recursos para a área (CARREIRA; PINTO, 2007). 
Nos interstícios desse período (final dos anos de 1970 e nos anos de 1980), Oliveira e Araújo (2005) acrescentam uma fase em que a qualidade foi medida a partir da ideia de fluxo, definido como número de estudantes que progridem dentro de determinado sistema. Assim, a comparação entre a entrada e a saída de alunos era a medida da qualidade de uma escola.

A mudança do período da década de 1980, no entanto, trouxe uma disputa conceitual sobre as dimensões da qualidade e de seus critérios de avaliação. De um lado, um grupo formado por educadores progressistas defendia que a qualidade da educação se baseava no atendimento, ao mesmo tempo, das demandas dos movimentos sociais e dos problemas revelados pelos estudos existentes nas escolas públicas.

Do outro lado, grupos com interesses conservadores argumentavam que a expansão das matrículas levou à perda da qualidade. Defendiam a criação de indicadores de avaliação comparativos entre as escolas (CASASSUS, 2009), na medida em que não era mais possível verificar a qualidade dos sistemas unicamente sob os aspectos da exclusão e da repetência (XIMENES, 2014).

Ainda que a primeira vertente tenha obtido conquistas na Constituinte de 1988 e, mais à frente, nas Leis de Diretrizes e Bases de 1996, o que se observou foi a prevalência da mudança nos padrões de qualidade a partir da avaliação da totalidade do sistema educacional (OLIVEIRA; ARAUJO, 2005; FONSECA, 2009).

Na década de 1990, sob os governos de Fernando Collor e Fernando Henrique Cardoso, os sistemas de avaliação e monitoramento adotaram indicadores de avaliação de grande alcance. Para tal, a nova política se centrou na mudança da regulação do sistema, apoiando se na qualidade interpretada como sen $\neg$ do equivalente à pontuação em uma prova estan $\neg$ dardizada (CASASSUS, 2009; MARCHELLI, 2010). A padronização de indicadores de qualidade manteve continuidade nos 16 anos seguintes do Governo do Partido dos Trabalhadores, aprofundando os parâmetros de comparação ao investir recursos financeiros e técnicos na ampliação do sistema em larga escala (FREITAS, 2007; FERREIRA, 2017).

Nessa perspectiva, os processos formativos se baseiam em resultados quantificáveis que medem desempenhos e servem de informação básica aos índices. Por sua vez, tais índices se transformam em classificações e rankings, que atendem ao mercado e supostamente atestam a "qualidade" dessas instituições (DIAS SOBRINHO, 2008; THIENGO et al., 2018).

Ao analisar os indicadores nacionais de desempenho como parâmetro de qualidade, Almeida, Dalben e Freitas (2013) abordam que a lógica se baseia em avaliações externas, através de um aparato normativo-jurídico que não considera 
as particularidades de cada instituição de ensino, mas a média do desempenho cognitivo de determinada turma. Ademais, ao aplicar uma prova padronizada e ranquear as escolas com base nas notas dos estudantes, a qualidade é jogada para a perspectiva de responsabilizar a escola, expondo à sociedade seus resultados, sem considerar as condições específicas e desiguais entre as diferentes instituições (FREITAS, 2007).

Com base na breve retomada dos planos de educação no Brasil, é possível notar que a qualidade é um construto imbricado nos distintos paradigmas de interpretação da educação (MOROSINI, 2001). Logo, analisar a qualidade é compreender que se trata de uma categoria histórica e socialmente construída, cujos discursos se alteram no tempo e no espaço, vinculando-se às demandas de um dado processo (XIMENES, 2014; FERREIRA, 2017). Desse modo, a qualidade emerge como um conceito em constante disputa, onde diferentes setores se mobilizam frente às distintas concepções político-pedagógicas que possuem (CURY, 2010).

No caso brasileiro, ao se analisar o período de 1933 a 2016 é possível notar mudanças nas concepções dos padrões e mecanismos de avaliação da qualidade. Apesar disso, observam-se continuidades na maior parte dos planos nacionais, cuja lógica formadora é a mão de obra para o mercado de trabalho. Para compreender o momento atual (2017 a 2019), torna-se necessário investigar as visões que justificam a expansão das pedagogias militares, bem como o que entendem por qualidade nesse modelo educacional.

\section{AS NARRATIVAS DA QUALIDADE NA MILITARIZAÇÃO DA EDUCAÇÃO BÁSICA}

Enquanto o primeiro colégio militar surgiu em 09 de março de 1889, no Rio de Janeiro, o formato de militarização das escolas emerge a partir de 2001, em parcerias estabelecidas entre as escolas públicas e a polícia e bombeiros militares (VELOSO; OLIVEIRA, 2016).

O contexto foi marcado por argumentos de que a escola pública projetada na transição do regime ditatorial para a democracia havia fracassado, o que acarretava a urgência de se pensarem outros mecanismos para as escolas. 
De acordo com entusiastas, deveriam proporcionar a diminuição da violência, indisciplina e evasão, emergindo, assim, narrativas em defesa da criação e expansão de modelos militares (GUIMARÃES; 2017) 3 .

Como exemplo, em 2012, período em que se expande o processo de militarização das escolas, a emissora Globo de Televisão realizou duas coberturas jornalísticas apresentando "casos de sucesso" na área. A primeira, uma reportagem divulgada no Programa de abrangência nacional, O Bom Dia Brasil. A matéria de 2 minutos e 41 segundos inicia com a fala do repórter Chico Pinheiro sobre as questões da qualidade e desempenho nos indicadores nacionais:

Desigualdade, injustiça social se combate com educação de qualidade para todos! E entre os resultados do IDEB, olha que surpresa... Foram divulgados na semana passada e chama a atenção esse detalhe, das 30 melhores escolas públicas do país, 12 são militares (G1, 2012).

A narrativa estabelece uma analogia de que as melhores escolas são aquelas que obtiveram altos desempenhos nas provas nacionais de avaliação. Dessa forma, infere-se que o bom resultado no IDEB é o que determina o padrão de qualidade da educação.

Durante a matéria, são citados os desempenhos de escolas militarizadas sob a gestão das Polícias Militares de Anápolis (Goiás) e de Manaus (Amazonas), ilustrando-as com os maiores resultados em seus respectivos Estados. Além disso, três tradicionais colégios militares ligados ao exército foram referenciados (Curitiba, Salvador e Belo Horizonte) entre os dez melhores do ranking geral da rede pública.

No mesmo ano, uma matéria transmitida pela filiada da Rede Globo tinha como título "Colégio Militar de Porto Alegre mostra segredo da qualidade de ensino". A reportagem de 8 minutos e 12 segundos inicia com o relato denominado de "sucesso" da escola militar que teve uma aluna campeã do soletrando:

3 Diferente da narrativa supracitada, os dados do Censo da Educação mostraram resultados distintos nas últimas décadas. O investimento em educação triplicou entre 2003 a 2014, a qualidade do ensino básico melhorou e não caiu. A nota da educação básica cresceu nos três ciclos do indicador que mede a qualidade do ensino, o IDEB. No ensino fundamental, subiu de 3,8 em 2005, para 5,5 em 2015, nos anos iniciais e de 3,5 para 4,5 nos anos finais. No ensino médio, cresceu de 3,4 em 2005, para 3,7 em 2015 (AFONSO, 2018). 
Você já deve ter ouvido falar da qualidade das escolas militares. No último sábado, uma aluna do colégio militar aqui da capital foi a campeã do soletrando, o programa do caldeirão do Luciano Huck. Pela instituição já passaram muitos nomes ilustres como ex-presidentes e o poeta Mario Quintana. Mas, qual será o segredo dessas escolas para ter um ensino tão reconhecido? [...] Que fórmula pedagógica é essa capaz de impulsionar os estudantes à beira da excelência? $\mathrm{O}$ que faz destas instituições um centro de formação de alunos tão bem sucedidos? $(\mathrm{G} 1,2012)$.

A matéria assume enquanto pressuposto que há um "segredo", uma "fórmula" pedagógica que conduz à excelência, desconsiderando, contudo, as condições estruturais, financeiras e perfis socioeconômicos dos estudantes para o suposto sucesso. Além disso, a qualidade da educação é associada aos desempenhos acadêmicos em provas nacionais e nas ditas figuras "ilustres" que passaram pela instituição.

Para adentrar os "segredos" do colégio militar de Porto Alegre, a reportagem entrevista uma aluna que enfatiza "a fórmula pedagógica": aprendizado e seguir as tradicionais normas militares, como o uso do uniforme e cumprimento de comportamentos inspirados nas forças armadas. Ao final, resgata a ideia de que a qualidade é medida pelo indicador IDEB, o que justificaria a excelência do colégio, ao estar acima da média nacional.

Com base nas matérias citadas, a qualidade da educação parece resgatar ideais instaurados no Estado Novo, em 1937. Naquela época, a formação educacional havia não só recebido influência dos setores militares, como também utilizava da moral cívica no propósito de naturalizar os valores ditos centenários das forças armadas: Hierarquia e a disciplina dos Homens. Porém, outra dimensão da qualidade foi acrescida: Processos formativos baseados em resultados quantificáveis. A mensuração do desempenho por indicadores transformada em rankings, representando numericamente a "qualidade" das instituições.

Em 2015, a mesma narrativa foi utilizada para fomento e expansão do processo de militarização das escolas no Estado de Goiás. O governo, ao encaminhar à Assembleia Legislativa um projeto para a militarização de escolas, apresentava como justificativa "os bons resultados deste modelo, que proporcionam rigoroso padrão de qualidade, primeiro lugar no IDEB de Goiás e destaque no ENEM". Ademais, "os colégios militares têm sua efi $\neg$ cácia e credibilidade atestadas pela comunidade, nos ensinamentos de cidadania que são ministrados, com destaque para o respeito ao cidadão", o que acarreta a "ampliação do padrão de qualidade" (ALVES; TOSCHI; FERREIRA, 2018, p. 277). 
No ano de 2019, em um contexto de intensos cortes de verbas para a educação pública, o Governo Federal tem proferido narrativas em defesa do aumento de colégios militares e da militarização das escolas na esfera pública. $\mathrm{Na}$ comemoração dos 130 anos do Colégio Militar do Rio de Janeiro, o presidente da república enfatizou:

Estamos fazendo no Campo de Marte, na capital de São Paulo, o maior colégio militar do Brasil. Queremos preparar os jovens para a quarta revolução industrial. Desta forma mudaremos o destino no Brasil. [...] As escolas militares honram todos os brasileiros com a educação básica e são bem colocadas nos rankings dos Estados. Queremos colocar colégios militares em todos os Estados do Brasil (LUNA; DOLZAN, 2019).

A narrativa apresenta similaridades com ideais de qualidade sustentados durante a ditadura militar. Naquela época o Ministério da Educação (BRASIL, MEC, 1971) expressava a qualidade a partir da formação de um cidadão capaz de participar eficazmente das atividades produtivas da nação. Enquanto isso, o atual presidente lança mão da expressão preparar os jovens para a "quarta revolução industrial". No pano de fundo, reproduz a ideia de uma educação para formar um indivíduo útil e disciplinado para o mercado, porém, agora se apoiando na qualidade mensurada a partir de provas estan $\neg$ dardizadas.

Enquanto ações para ampliar essa concepção de qualidade, o Decreto $\mathrm{n}^{\mathrm{o}} 9.665$, de 2 de Janeiro de 2019, institui a subsecretaria de fomento às "Escolas Cívico-Militares". O artigo 1 do Capítulo I da Estrutura Regimental do Ministério da Educação, estabelece: "O Ministério poderá estabelecer parcerias com instituições civis e militares que apresentam experiências exitosas em educação" (BRASIL, 2019, parágrafo único).

A expressão 'experiências exitosas' reproduz não só a visão das ditas 'best pratices' comum no mundo dos negócios, como abre espaço para a correlação com educação de qualidade a partir dos modelos de instituições militares. A referência 'do êxito' também estabelece aproximações com as pedagogias militares:

À Subsecretaria de Fomento às Escolas Cívico-Militares compete propor e desenvolver um modelo de escola de alto nível, com base nos padrões de ensino e modelos pedagógicos empregados nos colégios militares do Exército, das Polícias Militares e dos Corpos de Bombeiros Militares, para os ensinos fundamental e médio (BRASIL, 2019, art. 16, II).

$\mathrm{Na}$ passagem, é possível registrar que a adesão aos modelos de escolas militarizadas implica a replicação das práticas de gestão administrativa e educacional como também a utilização de processos pedagógicos, considerados referência para desenvolver uma escola dita de 'alto nível'. 
Enquanto o decreto lança mão de expressões como "experiências exitosas" e "alto nível" para tratar da militarização da educação, o texto reproduz 32 vezes a palavra qualidade, ao associá-la a ações, práticas, processos e avaliações que envolvem a Educação Básica, Educação Técnica, Educação Profissional e Educação Superior. Contudo, suas concepções são vagas, não definindo o que se entende por qualidade, mas inferindo a utilização de indicadores para mensuração dos seus padrões:

Compete à Subsecretaria de Fomento às Escolas Cívico-Militares:

VI - promover a melhoria da qualidade da educação básica em todas as suas etapas e modalidades a partir do estabelecimento de objetivos, metas e indicadores que visem ao alcance, validade, qualidade e efetividade das políticas, programas e ações propostas; [...] IX - subsidiar a implementação da política nacional curricular, em alinhamento com o Sistema Nacional de Educação, e estabelecer parâmetros de qualidade tanto para as condições de oferta da educação básica quanto para a aprendizagem dos estudantes (BRASIL, 2019, artigo 11 - grifo nosso).

Em complemento, o governo elaborou o texto intitulado 'Compromisso Nacional pela Educação Básica’. Em um formato próximo ao uso de slides de PowerPoint, apresenta um conjunto de propostas para a Educação até o ano de 2030, que, entretanto, não dialoga com as metas do Plano Nacional de Educação 2014-2024.

O texto afirma que o Brasil apresenta baixos resultados no Programa Nacional de Avaliação de Estudantes (PISA) quando comparado aos países latinos (Chile, Uruguai, Trinidad Tobaco, Argentina, Costa Rica, México e Colômbia), o que indica a necessidade da elevação da qualidade da educação.

Porém, estabelece que o baixo rendimento não implica uma relação linear entre gastos em educação e qualidade. Ao referenciar os resultados das notas do PISA de 2015, ranqueia o Brasil com outras nações com desempenhos similares, que supostamente investiram menores verbas. Não é por menos que, após a divulgação do documento, o Ministro da Educação reafirmou a ideia de que não é necessária a manutenção das propostas de 10\% do PIB, aprovadas no PNE 20142024 para aumentar a qualidade da Educação Básica, mas a utilização eficiente dos recursos.

O pacote de ações educacionais encerra com a proposição de impulsionar a militarização das escolas. A meta indica a criação anual de 27 escolas, totalizando 108 novas até o final de 2023. Para justificar o modelo, o documento esboça um gráfico (FIGURA 1) com os dados do IDEB entre os anos de 2005 a 2017, referenciando a superioridade da qualidade dos colégios militares (federais) e escolas militarizadas frente à rede pública tradicional (civil). 


\section{Figura 1 - Desempenho das escolas Públicas no Brasil}

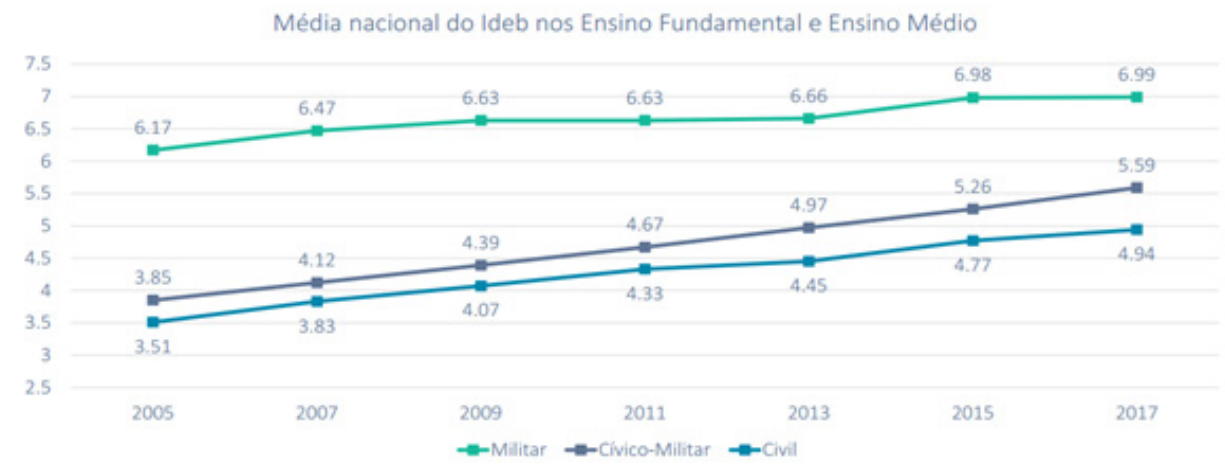

FONTE: BRASIL/MEC, p.29, 2019.

Chama a atenção que os resultados englobam em um mesmo grupo (civil) os Institutos e Centros Tecnológicos federais que apresentam desempenhos semelhantes aos colégios militares e às escolas militarizadas. Ao diluírem as instituições e os colégios técnicos federais junto ao montante das demais escolas públicas e civis, o resultado joga para o topo do ranking as escolas com pedagogias militares como únicas no padrão de 'excelência' de educação.

Não parece coincidência que no ranking relativo ao desempenho das escolas públicas do ENEM de 2016, o INEP, sob o governo de Michel Temer admitiu ter cometido o equívoco de excluir 96\% dos Institutos e escolas federais da classificação que mensura a qualidade (MORENO, 2016). Refeita a inclusão no ano posterior, das 10 melhores instituições públicas do ENEM em 2017, sete eram colégios de aplicação das universidades federais, Institutos federais e Centros Tecnológicos (ANDES, 2019).

Por fim, a narrativa da qualidade na militarização escolar não considera as particularidades de cada instituição, mas a média do desempenho cognitivo de determinada turma. Ao aplicar uma prova padronizada e ranquear as escolas com base nas notas dos estudantes, a qualidade é jogada para a perspectiva de responsabilizar a escola, expondo à sociedade seus resultados, sem considerar as classes de igualdade entre as diferentes instituições. 


\section{CONDIÇÕES PARA A QUALIDADE NAS ESCOLAS MILITARIZADAS}

Ao analisar as condições políticas das escolas militarizadas que sustentam o dito padrão de qualidade, uma primeira dimensão é o recurso financeiro. Enquanto o investimento médio por aluno em escolas públicas civis é de aproximadamente $\mathrm{R} \$ 6$ mil por ano, os treze colégios militares federais recebem três vezes mais, $\mathrm{R} \$ 19$ mil ao ano, de uma fonte específica, o ministério da Defesa (CAFARDO; JANSEN, 2018).

As escolas militarizadas também apresentam particularidades em comparação com a rede básica de ensino público. Se o recurso é o mesmo do Ministério da Educação, muitas adotam estratégias para ampliar as fontes por meio de "contribuições voluntárias". No estado de Goiás, que possui 46 escolas dessa natureza, até o final de 2018 cobrava-se a compra de uniforme militar (entre $\mathrm{R} \$ 250$ e $\mathrm{R} \$ 350$ ), o pagamento de matrículas, rematrículas, apostilas e até taxas mensais (CUNHA, 2019).

Em virtude de tais condutas, o Ministério Público do Estado de Goiás ${ }^{5}$ lançou um ofício a todos os promotores informando que as cobranças nas escolas militarizadas são ilegais e abusivas à luz da Constituição do Estado, que prevê a gratuidade do ensino público em estabelecimentos oficiais ${ }^{6}$ (TOKARNIA, 2018).

Outra condição para a qualidade é o modo de acesso e o perfil dos estudantes da rede pública básica. Enquanto a maioria das escolas públicas adota o acesso amplo (sem provas para inclusão) e têm seu quadro composto por estudantes cujo nível socioeconômico é médio, nos treze colégios militares do exército, o nível socioeconômico é considerado muito elevado.

Além disso, o acesso é mais restritivo, já que possuem reservas de vagas $(70 \%)$ aos dependentes legais de militares. O restante $(30 \%)$ inclui um intenso processo seletivo por meio de provas de admissão, na qual em instituições como o Colégio Militar de Porto Alegre e Belo Horizonte, o índice supera 70 candidatos por vaga (MUZZI, 2015).

\footnotetext{
4 A Polícia Militar denomina essa cobrança de "contribuição voluntária” não obrigatória e é destinada para prover as despesas gerais com escopo de melhorar a qualidade do serviço, de acordo com o Regimento Interno que versa sobre a contribuição (GUIMARÃES, 2017).

$5 \quad$ No estado do Amazonas o Ministério Público também ajuizou uma ação civil pública para coibir as cobranças nas escolas ligadas a Policia Militar do Estado.

6 Diferente das escolas militarizadas, os colégios militares ligados às forças armadas continuam com as cobranças de taxas. No dia 24/10/2018 o Supremo Tribunal Federal autorizou a cobrança de mensalidades nos trezes colégios do Brasil ao informar que as contribuições estão previstas na Lei Federal n 9.786/99.
} 
As escolas militarizadas também exibem um perfil socioeconômico distinto da maioria das escolas da rede pública. Em pesquisa realizada por Saddi (2015), no Estado de Goiás, praticamente não havia estudantes com renda menor que um salário mínimo. Registrou-se apenas 5\% com renda de um salário e a maioria entre cinco e sete salários, o que caracteriza por um perfil socioeconômico médio-alto e alto ${ }^{7}$.

As escolas militarizadas fazem o uso de reservas de vagas para dependentes de militares da Polícia, Corpo de Bombeiros e integrantes das Forças Armadas. Um caso emblemático é o Estado do Rio de Janeiro, onde, no começo de 2019, os editais de seleção para estudantes de três escolas controladas pela Polícia Militar fixaram uma reserva de $90 \%$ das vagas para filhos de policiais ${ }^{8}$ (SABOIA, 2019).

Enquanto a reserva implica um filtro para a composição de perfis socioeconômicos distintos entre as três categorias de escolas públicas, o processo ainda tende a gerar o 'efeito Harvard'. Ou seja, as instituições de prestígio recebem estudantes mais preparados e é admissível que tenham um desempenho relativo maior que os demais.

Isto significa que a concepção de qualidade nas escolas militarizadas não considera as especificidades ao estabelecer comparações. Os resultados não necessariamente podem ser atribuídos ao "êxito" ou à 'fórmula pedagógica', mas às condições que são oferecidas, já que as colocam em vantagem frente às demais escolas públicas (CRUZ, 2017).

A condição para a dita qualidade da militarização implica ainda conflitos com a legislação anterior. Se os colégios militares são regidos exclusivamente pelo exército, nas escolas militarizadas a estrutura organizacional tem permitido a indicação de policiais militares para funções de diretor militar, de disciplinas e tutores, que atuam nas unidades de ensino conveniadas.

A nomeação para as funções tende a seguir livremente a escolha pela Polícia Militar entre os membros da corporação, sem a exigência de formação específica feita pela Lei de Diretrizes e Bases da Educação (LDB 9.394/1996). O modelo adotado diverge da Constituição Federal, em seu artigo 206, inciso V, que dispõe: "os profissionais da educação escolar das redes públicas ingressarão na carreira exclusivamente por concurso público de provas e títulos".

A militarização da educação afasta também da Gestão Democrática (elucidada na meta 19 do Plano Nacional de Educação 2014-2024). Se não é novidade que os modos participativos não fazem parte dos colégios militares,

\footnotetext{
$7 \quad$ Fenômeno semelhante foi registrado nas escolas militarizadas do estado da Bahia.

$8 \quad$ No Estado da Bahia, as escolas militarizadas sob a gestão da Polícia Militar reservam 50\% das vagas das unidades do interior e 70\% nas vagas da Capital para filhos de militares estaduais e servidores públicos civis da corporação.
} 
Santos (2016) afirma que o regulamento das escolas militarizadas coíbe a participação. Não há previsão regimental indicando a necessidade de se discutirem coletivamente os rumos da aprendizagem, nem mecanismos de interação e discussão dos problemas internos, cabendo-lhes seguir as normas e regras estabelecidas.

Algumas desconsideram direitos previstos no Estatuto da Criança e do Adolescente (ECA), como no Estado de Goiás e da Bahia: usar óculos esportivos, boné, tiaras, ligas coloridas ou outros adornos, quan $\neg$ do uniformizados (violação de natureza leve);apresentar-se com o cabelo fora do padrão, deixando soltos com pontas ou mechas caídas, ou tingido de forma extravagante (violação de natureza média); manter contato físico que denote envolvimento de cunho amoroso quando devidamente uniformizado, dentro do Colégio ou fora dele (natureza grave); provocar ou tomar parte, uniformizado ou estando no Colégio, em manifestações de natu $\neg$ reza política (natureza grave) (VELOSO; OLIVEIRA, 2016; MINISTÉRIO PÚBLICO FEDERAL, 2018).

Não é por menos que no Estado da Bahia foi instaurado um inquérito civil público no âmbito da Procuradoria Regional dos Direitos do Cidadão para apurar a implantação da metodologia nas escolas públicas. Da mesma forma, o Ministério Público recomendou que as escolas militarizadas se abstenham de violar ou restringir a intimidade e vida privada dos estudantes. Propõe-se proibir a imposição de padrões estéticos quanto ao estilo de cabelo, unhas, formas de vestir e uso de acessórios (Idem).

Conforme se observa, a militarização modifica a estrutura das escolas baseando-se na conjugação de consenso e de coerção, tendo em vista a necessidade de assegurar, por um lado, a hegemonia do conjunto da sociedade em relação à emergência dos novos modelos de gestão e, por outro lado, conformar corpos e mentes dos discentes às estratégias de disciplina e hierarquia de uma instituição militarizada (GUIMARÃES, 2017).

Em outras palavras, no modelo militarização os estudantes não são sujeitos, mas objetos de intervenção e alvos de mecanismos disciplinares de conformação e normalização. Assim, cabe questionar se realmente seria esse o papel da educação que se espera na formação de jovens, marcada por sua submissão e pelo esvaziamento de sua capacidade de ação política.

Além disso, a narrativa de que as pedagogias militares se apresentam como um novo modelo a ser seguido, parece atingir os professores da rede estadual, pois se volta às questões pedagógicas. Subliminarmente, a mensagem pode expressar que os professores da rede estadual pública não têm competência para produzir bons resultados, sendo necessário, por isso, transferir as escolas 
para a Polícia e Bombeiros Militares (ALVES; TOSCHI; FERREIRA, 2018), sem tocar em questões como a falta de valorização desses profissionais e a redução de recursos destinados à educação pública.

\section{CONSIDERAÇÕES FINAIS}

Ao analisar as concepções de qualidade no modelo de gestão militarizada nas escolas, ainda que se busque sustentar uma narrativa do resgate da autoridade do professor e em seguir normas militares tradicionais, reproduz-se a mesma lógica dos sistemas comparativos e padronizados de avaliação para mensuração. $\mathrm{Ou}$ seja, tais indicadores quantitativos ocultam a importância de aspectos pedagógicos fundamentais para o pleno desenvolvimento e para uma formação (e por isso cidadã) dos jovens brasileiros. A qualidade defendida se mostra como fruto dos desempenhos obtidos nas provas do IDEB e ENEM; porém, os vieses da narrativa não consideram as condições políticas que sustentam os supostos resultados.

Conforme visto, a militarização das escolas públicas tem sido marcada por: (i) maiores recursos aos colégios militares federais, (ii) estratégias de cobranças voluntárias nas escolas militarizadas; (iii) reserva de vagas para dependentes de militares; (iv) maior acesso a estudantes com um perfil socioeconômico alto. Com base em tais singularidades, pode-se deduzir que a tomada de decisões políticas sobre o orça $\neg$ mento e mudanças no processo seletivo pode aumentar a dita qualidade das demais escolas, sem qualquer necessidade da transformação de escolas públicas em colé $\neg$ gios militarizados (VELOSO; OLIVEIRA, 2016).

Outro fator a ser considerado é que as escolas militarizadas ao adotarem reservas de vagas, selecionam o seu público, ação que impulsiona vantagens quantitativas nos processos de avaliação pedagógica e nos indicadores de qualidade. No entanto, isso revela um mecanismo de reprodução das desigualdades, visto que as demais escolas públicas recebem todos os segmentos sociais num contexto político de subsequentes reduções dos investimentos públicos.

Ademais, sob o pretexto do aumento da qualidade da educação, a militarização não só se distancia da gestão democrática escolar, como aponta para incongruências frente à Constituição Federal de 1988, ao Estatuto da Criança e do Adolescente (ECA) e à Lei de Diretrizes e Bases da Educação (LDB 9.394/1996), ao permitir a inserção de professores militares sem concursos e formação na área, bem como adotar normas e regras militares que violam ou restringem a intimidade e vida privada dos estudantes. 
É válido destacar que no presente artigo não se discutiram as peculiaridades existentes nos processos de militarização de escolas estaduais e escolas municipais, considerando suas diferentes nuances. Nesse sentido, a título de proposta para novas agendas de pesquisa, sugere-se a discussão aprofundada das metodologias específicas e dos distintos processos de militarização que têm sido levados a cabo em escolas públicas pertencentes tanto ao nível estadual quanto municipal.

Em conclusão, na medida em que o espaço público passa a ser estruturado de forma militarizada sob a égide da disciplina e da hierarquia, o modelo aprofunda a narrativa da dita necessidade de aumento de qualidade da educação brasileira, servindo, entretanto, aos interesses do mercado através da formação de mão de obra qualificada em indicadores padronizadores, porém, também dócil e obediente à manutenção da ordem vigente do sistema.

\section{REFERÊNCIAS}

AFONSO, N. Bolsonaro e educação: erros do presidente eleito sobre analfabetos, Pisa e investimentos. Folha Online, 2018. Disponível em: https://piaui.folha. uol.com.br/lupa/2018/12/27/bolsonaro-educacao-analfabetos. Acesso em: 09 abr. 2019 .

ALMEIDA, L, C; DALBEN, A; FREITAS, L, C. O IDEB: limites e ilusões de uma política educacional. Educação \& Sociedade, Campinas, v. 34, n. 125, p. 1153-1174, out/dez. 2013.

ALVES, M; TOSCHI, M; FERREIRA, N. A expansão dos colégios militares em Goiás e a diferenciação na rede estadual. Revista Retratos da Escola, Brasília, v. 12, n. 23, p. 271-287, jul./out. 2018.

ANDES. Escolas federais custam três vezes menos e têm desempenho superior que colégios militares. Artigos/Destaques. 2019. Disponível em: https:// www.andes.sindoif.org.br/2019/01/08/escolas-federais-custam-menos-e-temdesempenho-superior-que-colegios-militares/. Acesso em: 09 abr. 2019.

BRASIL. Decreto $\mathbf{n}^{\mathbf{0}} \mathbf{9 . 6 6 5}$, de 2 de janeiro de 2019. Brasília: Senado Federal, 2019.

BRASIL. Ministério da Educação. I Plano Setorial de Educação e Cultura 1972-74. Brasília: MEC, 1971. 
BRASIL. Ministério da Educação. Compromisso Nacional Pela Educação Básica, 2019. Disponível em: http://portal.mec.gov.br/images/11.07.2019_ PPT-Cafe-da-manha-EB-converted.pdf. Acesso em: 30 ago. 2019.

CABRAL, J. A militarização da escola: um debate a ser enfrentado. 2018. 145p. Dissertação (Mestrado em Desenvolvimento Humano) - Universidade de Taubaté, Taubaté, 2018.

CABRITO, B. Avaliar a qualidade em educação: Avaliar o quê? Avaliar como? Avaliar para quê? Cadernos Cedes, Campinas, v. 29, n. 78, p. 178-200, mai/ago. 2009.

CAFARDO, R; JANSEN, R. Estudantes de colégios militares custam três vezes mais ao País. O Estado de São Paulo, 2018. Disponível em: https://politica. estadao.com.br/noticias/eleicoes,estudantes-de-colegio-militar-custam-tresvezes-mais-ao-pais, 70002473230. Acesso em: 09 abr. 2019.

CAMPOS, A. Militarização das escolas tem apoio majoritário da população do DF. Correio Braziliense, 2019. Disponível em: https://blogs.correiobraziliense. com.br/cbpoder/militarizacao-das-escolas-tem-apoio-da-populacao-do-df/. Acesso em: 09 abr. 2019.

CARREIRA, D; PINTO, J.M.R. Custo aluno-qualidade inicial: rumo à educação pública de qualidade no Brasil. São Paulo: Global, 2007.

CASASSUS, J. Uma nota crítica sobre a avaliação estandardizada: a perda de qualidade e a segmentação social. Sísifo: Revista de Ciências da Educação, n. 09, pp 71-78, 2009.

CRUZ, L, A. Militarização das escolas públicas em Goiás: disciplina ou medo? 2017. 177p. Dissertação (Mestrado em História) - Pontifícia Universidade Católica de Goiás, Goiânia, 2017.

CUNHA, C. Número de Escolas Públicas Militarizadas cresce no Brasil. Atualidade, Vestibular UOL, 2019. Disponível em: https://vestibular.uol.com. $\mathrm{br} /$ resumo-das-disciplinas/atualidades/educacao---numero-de-escolas-publicasmilitarizadas-cresce-no-brasil.htm. Acesso em: 30 ago. 2019.

CURY, C, J. Qualidade em Educação. Nuances, v. 17, p. 17-34, 2010. 
DAVOK, D. Qualidade em educação. Avaliação, Campinas, v. 12, n. 3, p. 505513, 2007.

DIAS SOBRINHO, J. Qualidade, Avaliação: do SINAES a Índices. Avaliação, Campinas, v. 13, n. 03, p. 817-825, nov. 2008.

DOLZAN, M. Bolsonaro inaugura colégio para filhos de PMs e critica ideologia de gênero. Notícias, Terra, 2018. Disponível em: https://www.terra.com.br/ noticias/bolsonaro-inaugura-colegio-para-filhos-de-pms-e-critica-ideologia-degenero,a0a575f46d6eff1926e3075222fd84a057zke16v.html. Acesso em: 09 abr. 2019.

FERREIRA, E. B. A contrarreforma do Ensino Médio no contexto da nova ordem e progresso. Educação \& Sociedade, Campinas, v. 38, n. 139, p. 293-308, abr.-jun. 2017.

FONSECA, M. Políticas públicas para a qualidade da educação brasileira: Entre o utilitarismo econômico e a responsabilidade social. Gestão institucional e qualidade social da educação. Caderno Cedes, Campinas, v.29, n.78, 2009.

FREITAS, L, Carlos. Eliminação adiada: o ocaso das classes populares no interior da escola e a ocultação da (má) qualidade do ensino. Educação \& Sociedade, Campinas, v. 28, n. 100, p. 965-987, 2007.

G1. Escolas Militares se destacam entre as 30 melhores do país no IDEB. BOM DIA BRASIL, 2012. Disponível em: http://g1.globo.com/bom-dia-brasil/ noticia/2012/08/escolas-militares-se-destacam-entre-30-melhores-do-pais-noideb.html. Acesso em: 09 abr. 2019.

G1. Colégio Militar de Porto Alegre mostra segredo da qualidade de ensino. Bom dia Rio Grande do Sul, 2012. Disponível em: http://g1.globo.com/rs/riogrande-do-sul/bandeira-educacao/videos/t/todos-os-videos/v/colegio-militarde-porto-alegre-mostra-segredo-da-qualidade-de-ensino/2159664/. Acesso em: 09 abr. 2019.

GUIMARÃES, P. Os novos modelos de gestão militarizada das escolas estaduais de goiás. XXIX Simpósio Nacional de História. Anais... Brasília, 2017. 
LUNA, D; DOLZAN, M. Cotidiano. O Estado de São Paulo, 2019. Disponível em: https://noticias.uol.com.br/ultimas-noticias/agencia-estado/2019/05/06/ queremos-colocar-colegios-militares-em-todos-os-estados-do-pais-dizbolsonaro.htm. Acesso em: 30 ago. 2019.

MARCHELLI, P, S. Expansão e qualidade da educação básica no Brasil. Cadernos de Pesquisa, v. 40, n. 140, p. 561-585, 2010.

MINISTÉRIO PÚBLICO FEDERAL. Recomendação No 04/2019/PRDC/ BA/MPF, Ilhéus, Bahia, 24 de Julho de 2019.

MORENO, A. Governo exclui $96 \%$ dos institutos federais em divulgação do ENEM por escola. Educação, O Globo, 2016. Disponível em: https:// g1.globo.com/educacao/noticia/governo-exclui-96-dos-institutos-federais-emdivulgacao-do-enem-por-escola.ghtml. Acesso em: 09 abr. 2019.

MOROSINI, M. Qualidade da educação universitária: isomorfismo, diversidade e equidade. Interface - Comunic., Saúde, Educ, v. 5, n. 9, p. 98-102, 2001.

MUZZI, L. Colégios Militares crescem em meio à polêmica sobre ensino. Educação, O Tempo, 2015. Disponível em: https:/ / www.otempo.com.br/cidades/colegiosmilitares-crescem-em-meio-a-polemica-sobre-ensino-1.1111508. Acesso em: 30 out. 2019.

OLIVEIRA, R; ARAUJO, G. Qualidade do ensino: uma nova dimensão da luta pelo direito à educação. Revista Brasileira de Educação, São Paulo, n. 28, p. 5-23, jan./abr, 2005.

SABOIA, G. Maior espaço para filhos de PMs em escolas militares é questionado no Rio Educação Uol, 2019. Disponível em: https://educacao.uol.com.br/ noticias/2019/01/17/maior-espaco-para-filhos-de-pms-em-escolas-militares-equestionado-no-rio.htm. Acesso em: 30 ago. 2019.

SADDI, R. Colégio da Polícia Militar exclui os alunos mais pobres. Diário da Manhã, 2015. Disponível em: https://secom.ufg.br/p/11799-colegios-dapolicia-militar-excluem-os-alunos-mais-pobres. Acesso em: 30 ago. 2019. 
SANTOS, R, J. Militarização da escola pública em Goiás. 2016. 131p. Dissertação (Mestrado em Educação) - Pontifícia Universidade Católica de Goiás, Goiânia, 2016.

SANTOS; C; PEREIRA, R. Militarização e Escola Sem Partido: duas faces de um mesmo projeto. Revista Retratos da Escola, Brasília, v. 12, n. 23, p. 255-270, jul./out. 2018.

THIENGO; L; BIANCHETTI, L; DE MARI, C. Universidades de classe mundial: relações, desdobramentos e tendências. Educação \& Sociedade, Campinas, v. 39, n. 145, p.1041-1058, out.-dez, 2018.

TOKARNIA, M. MP de Goiás diz que cobrança de taxa por colégios militares é ilegal. Agencia Brasil EBC. Disponível em: http://agenciabrasil.ebc.com.br/ educacao/noticia/2018-12/mp-de-goias-diz-que-cobranca-de-taxa-por-colegiosmilitares-e-ilegal. Acesso em: 30 ago. 2019.

VELOSO, E, R; OLIVEIRA, N, P. Nós perdemos a consciência? Apontamentos sobre a militarização de escolas públicas estaduais de Ensino Médio no estado de Goiás. In: OLIVEIRA, I; SILVA, V (Orgs.). Estado de exceção escolar: uma avaliação crítica das escolas militarizadas. Aparecida de Goiânia: Escultura, 2016, p. $71-84$.

VIANNA, H. Avaliação do rendimento de alunos de escolas do $1^{\circ}$ grau da rede pública: um estudo em 20 cidades. Educação e Seleção, São Paulo, n.19, jan./ jun., 1989.

XIMENES, S, B. O conteúdo jurídico do princípio constitucional da garantia de padrão de qualidade do ensino: uma contribuição desde a teoria dos direitos fundamentais. Educação \& Sociedade, Campinas, v. 35, n 129, out-dez, 2014.

DANIEL CALBINO PINHEIRO é Docente do Programa de Mestrado em Educação da UFVJM. Doutor e Mestre Administração pela UFMG. Especialista em Filosofia pela UFSJ. Professor Adjunto da UFSJ.

E-mail: dcalbino@ufsj.edu.br

ORCID: http://orcid.org/0000-0001-8260-6126 
RAFAEL DIOGO PEREIRA é Doutor em Administração pelo Centro de PósGraduação e Pesquisas em Administração (CEPEAD) da Universidade Federal de Minas Gerais, na linha de pesquisa de Estudos Organizacionais e Sociedade, com realização de doutorado sanduíche junto a Universidad Complutense de Madrid, Espanha. Possui mestrado em Administração também pelo CEPEAD (2010). Graduado em Turismo, com ênfase em Gestão de Empreendimentos Turísticos, pela Universidade Federal de Minas Gerais (2006). Professor do Departamento de Ciências Administrativas da Faculdade de Ciências Econômicas da Universidade Federal de Minas Gerais. Pesquisador e Extensionista do Núcleo de Estudos Organizacionais e Sociedade (NEOS/UFMG).

E-mail: rdp.ufmg@gmail.com

ORCID: http://orcid.org/0000-0002-1057-2614

GERUZA DE FÁTIMA TOME SABINO é Doutora em sociologia pela Faculdade de Ciências e Letras de Araraquara - Unesp (2008), Mestre em Ciências Sociais pela Faculdade de Filosofia e Ciências de Marília - Unesp (2003) e graduada em Administração de Empresas pela Faculdade de Ciências Contábeis e de Administração de Marília - FEESR (1998). Atualmente é Professora Associada do Departamento de Computação, no curso de Sistemas de Informação da Universidade Federal dos Vales do Jequitinhonha e Mucuri - UFVJM.

E-mail: geruzaft@hotmail.com

ORCID: http://orcid.org/0000-0001-6326-3017

Recebido em agosto de 2019

Aprovado em setembro de 2019 